This is an Accepted Manuscript of a book chapter published by CRC Press Taylor and Francis Group in "Functional Pavement Design. Proceedings of the 4th ChineseEuropean Workshop on Functional Pavement Design (4th CEW 2016, Delft, The Netherlands, 29 June - 1 July 2016)" on 24 June 2016, available on line: https://www.crcpress.com/Functional-Pavement-Design-Proceedings-of-the-4thChinese-European-Workshop/Erkens-Liu-Anupam-Yiqiu/p/book/9781138029248 


\title{
Reuse of mining waste into innovative alkali-activated-based materials for road pavement applications
}

\author{
C. Sangiorgi \\ University of Bologna, Italy \\ C. Lantieri \\ University of Bologna, Italy \\ P. Tataranni \\ University of Bologna, Italy \\ J. Castro-Gomes \\ University of Beira Interior, Portugal \\ M. Gabriel \\ Beira Serra, Associação de Desenvolvimento Local, Portugal
}

\begin{abstract}
Based on the initial results obtained in the research program REMINE (H2020 RISE-Marie Curie Action) in progress, authors discuss the potential use of Panasqueira mine waste aggregates and fillers in the production of construction materials for transportation infrastructures. An estimate of the economic and social impact that this form of recycling could have on the local communities and on the perspective of other mining activities in Portugal and Europe is given. The main goals of the project are to explore materials design methods of alkaliactivated composites from mining/quarrying wastes based on the demanding requirement of rheology to fit for various processing techniques and applications. The development of artificial aggregates through alkali-activation of mining waste presents itself as a viable technical solution to compete with other commonly adopted materials and may lead to the manufacturing of less porous and harder aggregates for the production of most of the road paving materials.
\end{abstract}

\section{SOCIAL, ECONOMIC AND ENVIRONMENTAL IMPACT OF MINING ACTIVITIES}

\subsection{Panasqueira mine and its ores}

Panasqueira is one of the oldest underground mines in Portugal. The mine has been active for over 125 years. Panasqueira contains one of the largest economic viable tungsten vein deposits in the world. The tungsten is the main product of exploitation of Panasqueira. The mine is today operated by Sojitz Beralt Tin \& Wolfram (Portugal) SA.

The ore deposits consist of a series of stacked, sub-horizontal, hydrothermal quartz veins that lead into mineralized wolfram-bearing schists and shales (Cavey \& Gunning, 2006). The mineralized zone has dimensions of approximately $2,500 \mathrm{~m}$ in length, varying in width from $400 \mathrm{~m}$ to $2,200 \mathrm{~m}$, and continues to at least $500 \mathrm{~m}$ in depth.

Wolframite, cassiterite and chalcopyrite are the extracted minerals obtained. Such minerals are treated to make concentrates of tungsten, tin and copper, respectively. The current extraction methodology is a mechanized room-and-pillar method, based on an analysis of geological and geomechanical characteristics of the rock mass. The ore treatment process begins with heavy media separation for the coarse fractions of material. It enables removing about $80 \%$ of the ore that has no tungsten content. Afterwards, this pre-concentrated material is subjected to a conventional gravity concentration method, followed by sulphide removal using flotation and final dry magnetic separation (Franco et al., 2014).

Until 1996, the pre-concentrates were transported to the Rio plant, but today, the final separation procedures are carried out exclusively in the Barroca Grande plant. A huge tailings pile and two mud dams now exist at this site. One of the dams is still being fed with material with- 
out tungsten ore (mud, and coarse sterile material) obtained from the ore dressing operations (see Figure 1) (Ávila et al., 2008).
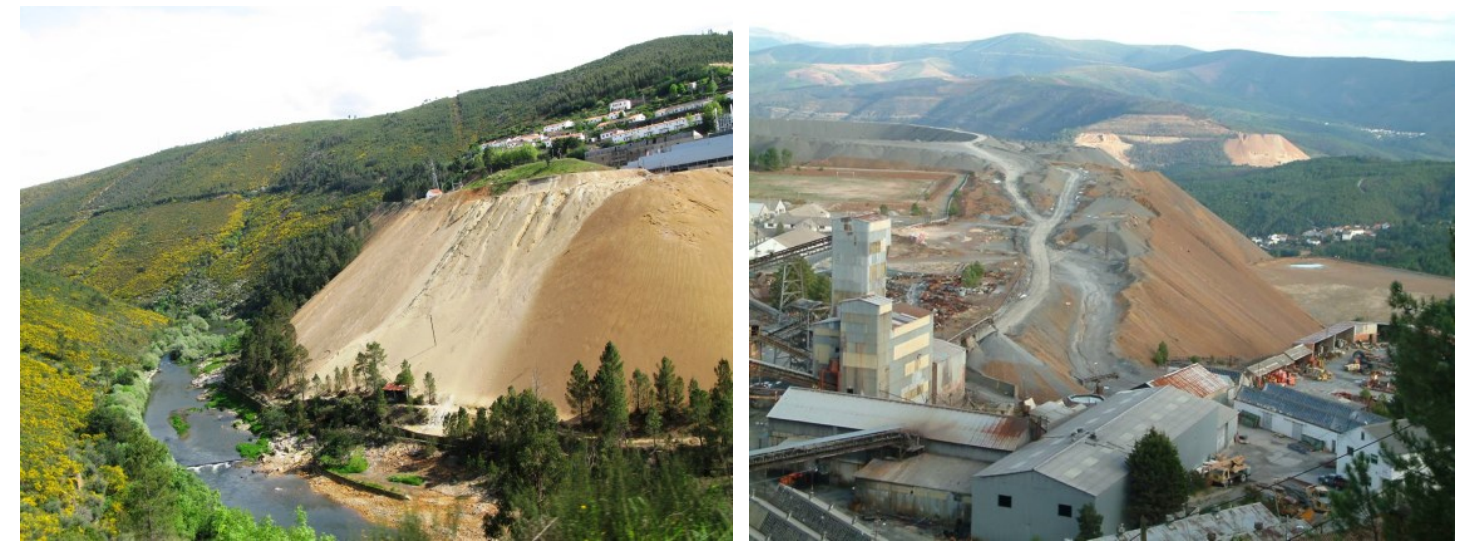

Figure 1. Left: Rio plant and old tailings piles. Right: Barroca Grande plant.

Accordingly to the initial records, during the first 50 years of mining over 27 million tons of rock were extracted, from which approximately a total of 92,800 tons of tungsten concentrate, 4,800 tons of tin concentrate, and 28,600 tons of copper concentrates were produced (Smith, 2006). Currently the production quantity is variable in the range of 85,000 to 95,000 tons of tungsten concentrate per year. The plant produces a high quality tungsten concentrate with $74 \%$ to $75 \% \mathrm{WO}_{3}$, which is one of the highest grades available on the market (Franco et al., 2014).

\subsection{Employment and impacts on Beira Interior}

The Panasqueira mine is the only operating tungsten extraction still active in Portugal. The Japanese Sojitz Corporation purchased the company in 2007 with an initial investment of 50 million euros, to which, according to the company, were added approx., 8 million euros more. In June 2014 the Sojitz Beralt Tin \& Wolfram (Portugal) SA employed more than 370 workers. However, more recently, in August 2015, less than 280 miners remained.

The company is facing problems mainly related to the international value of tungsten. Although global demand has not decreased, the price of the ore, namely Paratungstate Ammonium (APT), the product produced from the tungsten concentrate, has being continuously decreasing, being now below 200 dollars per MTU (Metric Ton Unit). Thus, due to the depreciation of the tungsten market value the company has been dismissing workers with fixed-term contracts and pensioners in the last year. According to the company, the APT standard value, for the mining in Panasqueira to be profitable should stand at a minimum of 350 dollars. In 2012, Panasqueira produced 1364 tons, which generated EUR 25.5 million. While in 2014, according to provisional data, Panasqueira produced 1070 tons, which generated revenues of EUR 18.4 million.

Regarding the environmental impact, Panasqueira is located near one of the highest mountains in Portugal, inside a Natural park, near the Sierra of Açor, that is one of the protected areas in the Country and also near the Zêzere River that is the second longest river in Portugal and the major source of water for the city of Lisbon.

Panasqueira mineral extraction and processing has produced, along years, primarily, two main types of mine tailings, accordingly to its grain size: coarse waste-rock tailings (sterile material) derived from rock blasting and waste-mud tailings (crushed and milled waste-rock) conveyed by pipelines into lagoons (mud dams), amounting to several million tons. Panasqueira heaps already assume enormous proportions; the Rio tailings (aprox. 1,200,000 $\mathrm{m}^{3}$ ) have one mud dam (aprox. $731,034 \mathrm{~m}^{3}$ ) and the Barroca Grande (aprox. 7,000,000 $\mathrm{m}^{3}$ ) has two mud dams (aprox. 1,193,885 $\mathrm{m}^{3}$ ) (Ávila et al., 2008). In the 1980's Panasqueira mining was generating about 300 tons of waste-rock tailings per day; currently, it is still generating 100 to 200 tons per day. Panasqueira tailings (particularly waste-mud) also contain high sulphide (As) concentrations and sulphide-related heavy metals $(\mathrm{Cu}, \mathrm{Pb}, \mathrm{Zn}$, and $\mathrm{Cd})$. It is now clear that oxidation of 
sulphides tailings and flow from open impoundments are the main source of pollution in the surrounding area and are responsible for the mobilization and migration of metals from the mine wastes into the environment (Ávila et al., 2008); (Godinho et al., 2010). Also, about 30\% of arsenopyrite (the main present sulphide) is rejected with the tailings (Ávila et al., 2008).

Thus, the accumulation of waste from Panasqueira mining activities, over the years, has lead to the formation of massive deposits. These deposits present today a potential risk of environmental pollution and cause serious landscape impacts, thus also affecting the quality of life of local populations.

\subsection{Current recycling of Panasqueira waste tailings and completed research}

The potential leaching of heavy metals, especially arsenic, from tungsten waste muds could represent a risk of toxicity for humans and the environment. Therefore, the safe reuse of this type of waste from Panasqueira is still rather limited not to cause other potential public health problems and environmental impacts (although there is potential for its safe and large scale reuse, as discussed in section 2.2.)

In turn, coarse wastes from Panasqueira tailings that are not contaminated with heavy metals are today safely reused in road pavements. However, the potential for reuse coarse wastes on a regional scale is primarily constrained by transport and consequently by economic aspects. Thus, there has been a rather limited reuse of such coarse wastes (not significant amounts) by local paving companies on low to medium traffic roads located in the region of Panasqueira, within a radius distance of about $60-70 \mathrm{~km}$.

The potential use of tailings in the production of emulsion based bituminous mixes with $100 \%$ coarse wastes from Panasqueira was recently evaluated. A research study carried on in 2006 at the University of Beira Interior showed that the physical and mechanical characteristics of these mixes and their low cost, could make them an adequate solution in low traffic volume pavements, namely in municipal and rural roads (Dinis de Almeida et al, 2006, Dinis-Almeida et al., 2016).

Other completed research studies have been focused in developing technical-artistic value added and polymer-based composite materials incorporating Panasqueira mining coarse wastes. Since waste-rock tailings have been exposed to weathering for many years they have undergone natural ageing, thus transforming them into coloured and textured rocks with high aesthetic value. Thus, considering their mechanical and physical characteristics, it is believed that there is enough potential for their reuse as new polymer-based construction materials in technicalartistic applications, particularly as terrazzo tiles for outdoor use, fulfilling CE marking requirements and in development of new polymer composites products make from the interception between the technological and artistic concept (Castro-Gomes et al., 2012).

\section{WASTE MATERIAL CHARACTERISTICS}

\subsection{Chemical, physical and mechanical data}

Typical chemical composition of waste-rock is presented in Table 1. Composition was determined by energy dispersive spectrometry (SEM/EDS) from milled samples of coarse materials. It consists mainly of silica and alumina with smaller percentage of iron and potassium, and other minor constituents, which make mud waste good for alkali-activation processes.

Table 1. Chemical composition of mud waste (\%)

\begin{tabular}{ccccccc}
\hline $\mathrm{SiO}_{2}$ & $\mathrm{Na}_{2} \mathrm{O}$ & $\mathrm{Al}_{2} \mathrm{O}_{3}$ & $\mathrm{Fe}_{2} \mathrm{O}_{3}$ & $\mathrm{~K}_{2} \mathrm{O}$ & $\mathrm{TiO}_{2}$ & Other minor oxides \\
\hline 68.54 & 1.14 & 18.27 & 5.64 & 5.24 & 1.17 & - \\
\hline
\end{tabular}

Table 2 presents physical and mechanical properties of waste-rock materials. Particle shapes were characterized on the basis of EN933-3 and EN933-4 standards for concrete aggregates. Coarse wastes are constituted by a major percentage of greywacke schist and about $10 \%$ of white quartz. Particles maximum and minimum dimensions were determined according to 
EN933-1 and EN12620. Mechanical and physical properties were determined by EN1097-2, EN1097-3, EN1097-6 and BS812-110.

From the test results, it is evident that waste coarse particles have good and consistent properties, equivalent to those found in good quality granite aggregates (Pereira et al., 2009). Wasterock tailings in Barroca Grande plant have the size like coarse aggregates (on average, diameter size of $5 \mathrm{~mm}$ and $25 \mathrm{~mm}$ ) and mud containing very fine particles (diameter size of less than 2 mm) (Antunes, 2009) (Castro-Gomes et al., 2012).

Table 2. Geometrical, physical and mechanical properties of coarse waste

\begin{tabular}{ll}
\hline Flakiness index & $\mathrm{FI}=27.7$ \\
Shape index & $\mathrm{SI}=53.2$ \\
Maximum dimension & $\mathrm{D}=25.40 \mathrm{~mm}$ \\
Minimum dimension & $\mathrm{d}=1.19 \mathrm{~mm}$ \\
& \\
Particle density & $2.73-2,81 \mathrm{~g} / \mathrm{cm}^{3}$ \\
Water absorption & $0.2 \%$ \\
Resistance to fragmentation (Los Angeles) & $19.2 \%$ \\
Aggregate crushing value & $16.5 \%$ \\
\hline
\end{tabular}

\section{ALKALI-ACTIVATION OF PANASQUEIRA MUD WASTE}

\subsection{Alkali-activation in brief}

In the 40's Feret and Purdon first studied the alkali-activation using ground granulated blast furnace slag (GGBFS) as precursor material. They utilized cement as alkali activator and also employed a solution of $\mathrm{NaOH}$. Alkali-activated mortars attained a compressive strength of 27 and $72 \mathrm{MPa}$, after 1 and 5 years, respectively (Feret, 1939), (Purdon, 1940). It was found out that the final product of alkali-activation of GGBFS is primarily made up of structures based on calcium silicate hydrate (Garcia et al., 2003). However, the C-S-H structure formed in the presence of high concentrations of $\mathrm{NaOH}$ was less dense than the normal $\mathrm{C}-\mathrm{S}-\mathrm{H}$ structure resulting from hydration of Portland cement (Bakharev et al., 1999). It is also possible to form structures in which the sodium is incorporated into the structure of the hydrated silicate gel $(\mathrm{N}-$ C-S-H) (Malolepszy, 1993).

Later, Glukhosvky began to study alkali activation from 1957 onwards with the objective of manufacturing special binders from materials containing low concentrations of calcium and high concentrations of silicon ( $\mathrm{Si}$ ) and aluminum (Al). These aluminum silicates that had been exposed to solutions containing alkaline metal compounds ( $\mathrm{Li}, \mathrm{Na}, \mathrm{K}, \mathrm{Rb}, \mathrm{Cs}$ - elements in the first group of the periodic table) exhibited similar hydraulic binding properties to those produced when using compounds of alkaline earth metals $\mathrm{Mg}, \mathrm{Ca}, \mathrm{Sr}, \mathrm{Ba}$ - elements in the second group). In this case, the matrix formed by alkali-activation of aluminosilicates using the alkaline solution is formed by $\mathrm{M}-\mathrm{A}-\mathrm{S}-\mathrm{H}$ gel, where $\mathrm{M}$ is the element of the first group of the periodic table ( $\mathrm{Na}+$ and $\mathrm{K}+$ are the most commonly used) (Krivenko, 2002)

Alkali-activation of waste materials is also a chemical process that makes it possible to transform glassy structures (partially or totally amorphous and/or metastable) into very compact well-cemented composites (Palomo et al., 1999). For polymerization to occur, a highly-alkaline medium is necessary to make it possible to dissolve a certain quantity of silicon and aluminum and to hydrolyze the surfaces of the particles of the raw materials (Van Jaarsveld et al., 1997). This medium can be created using alkaline solutions known as activators, alone or in combination, $\left(\mathrm{NaOH}, \mathrm{KOH}, \mathrm{Na}_{2} \mathrm{SiO}_{3}, \mathrm{Ca}(\mathrm{OH})_{2}\right.$, and others).

In general, all of these cementitious materials are obtained through the use of an alkaline medium, with or without clinker (precursor). However, they differ in terms of the raw materials, the types and concentrations of the activators, the kinetics of the reactions, the chemical reactions and, primarily, in terms of the structural arrangement of the chains that make up the matrix $(\mathrm{N}-\mathrm{A}-\mathrm{S}-\mathrm{H}$ has a three-dimensional structure and $\mathrm{C}-\mathrm{A}-\mathrm{S}-\mathrm{H}$ has a linear structure). Depending on the precursor materials and the alkaline activators used, both $\mathrm{N}-\mathrm{A}-\mathrm{S}-\mathrm{H}$ and $\mathrm{C}-\mathrm{A}-$ S-H gels can be present in the same alkali-activated matrix (Garcia Lodeiro et al., 2001). 
Currently, alkali-activated cements can be classified as the third generation of cements, since they are an alternative to ordinary Portland cement due to their superior properties, higher strength and durability, low shrinkage, low carbon emission, sulphate and acid resisting properties and hazardous waste encapsulation and environmental performance (Juenger at al., 2011, Vargas et al., 2014).

\subsection{Alkali-activation of waste materials from the Panasqueira mine}

Recent studies on the reuse of fine particles from mud tailings as precursor materials for alkaliactivated binders and applications have been conducted and are considered to be very promising from a technical, environmental and economic point of view.

Initially, these studies aimed to the development of a new alkali-activated binder by reusing the mud waste having, after a short thermal treatment, very good reactivity with alkaline activators. This new binder was investigated primary for its potential use as repair material of Ordinary Portland Cement (OPC) concrete. Preliminary results indicated such binder possesses very high bond strength even at the early ages and that its behavior was not affected by low surface treatment roughness. As well, cost comparisons showed that this alkali-activated repair solution was very cost effective (Pacheco-Torgal et al., 2009).

Later, artificial aggregates were developed from such alkali-activated mining waste mud mortars and their properties were studied as a potential substrate for fixed-film wastewatertreatment processes (biofilm reactors). The results showed that the obtained aggregates had suitable resistance to acid attack and may be used as substrate for fixed-film biological reactors for the treatment of acid wastewaters. Additionally, the appropriate porosity of the aggregates make them suitable for providing good adhesion and development of biofilm, essential for pollutant removal.

Hence, the development of artificial aggregates through alkali-activation of such mining waste mud for wastewater treatment by filtration, could be seen as a viable technical solution to compete with other commonly adopted materials (e.g. crushed natural stone or expanded clay (Silva et al., 2012).

\section{POTENTIAL USE OF TAILINGS IN THE ROAD CONSTRUCTION FIELD}

\subsection{Mine conversion and potential uses of tailings}

From what has been described, Panasqueira mine tailings could be seen as a potential source of materials for the construction industry of the Beira Interior region. From this perspective, a conversion of the mine production from mining to source of aggregates and construction products could be seen as a viable solution in case of unexpected closure or reduced mining activity.

The quantity and quality of tailings (fine and coarse) offers a wide, durable and economically feasible production alternative to the mine site and workers employment. Hence, a general plan of conversion could lead to the beginning of a new era in the use of rocks in the Panasqueira site. Partial machinery adaptation and areas conversion would be part of a long to medium-term business plan that should encompass the development of new alkali-activated products, together with aggregates mixtures for unbound and bituminous bound layers containing the tailings.

Figure 2, shows the potential use of tailings in the construction of roads. It is straightforward that an intense laboratory work should be performed in order to assess the most cost-effective use of materials: crushing, sieving, mixing with other aggregates sources should lead to the development of industrial set-up and procedures where impacts and wastes are minimized.

Environmental risks and contaminations should be evaluated according to the regulations in force. CE marking of aggregates and aggregates mixtures should be done in accordance with the European standards for unbound and bituminous bound products. 

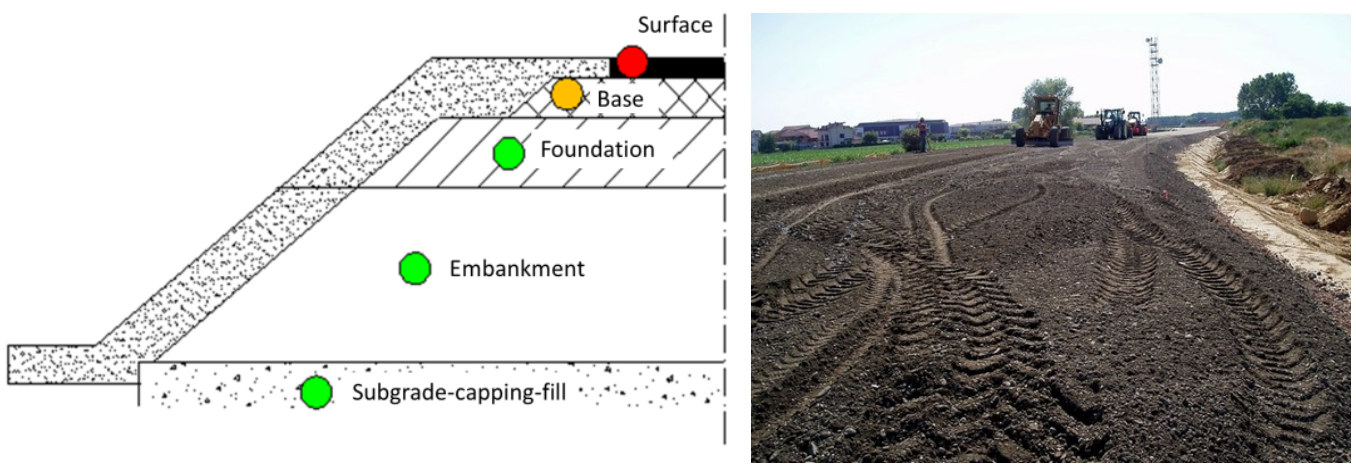

Figure 2. Potential use of tailings in road construction (left). Example of coarse tailings reuse (right).

\subsection{Use of Panasqueira tailings for bituminous bound layers}

At present, the number of asphalt concrete (AC) plants in the areas of Beira Interior (Fundao, Covilha, Belmonte) is limited and asphalt paving is managed from plants located either in Viseu or Coimbra as those in Covilha have been recently closed. Paving in remote locations like the Aldeia de Sao Francesco de Assis is expensive and only the use of mobile production plants can abate transportation costs and related impacts.

Nevertheless the position of the mine on the N238 national road between Fundao and Castelo Branco and the connection to Coimbra opens a potential market to the bituminous products that could be produced in Panasqueira with the use of its tailings. The installation of a stable asphalt plant with crushed and sieved stockpiles is feasible and could make use of large quantities of coarse and fine aggregates for different kind of bitumen bound materials.

Table 3 show a rough estimate of the aggregates (coarse and fines) consumption for the production of one square meter of 3 layers flexible pavement. Thicknesses have been chosen according to the most common pavement design in the area of Panasqueira. Binder percentage and mixture density have been assumed from previous specifications. A total of more than 430 $\mathrm{kg}$ of tailings could be used for each pavement square meter, in this example where asphalt concrete particles are entirely coming from the mine tailings. Specific mix-design should be performed in order to maximize and optimize the amount of tailings in the recipe, as well as different virgin aggregates and reclaimed asphalt pavement aggregates should be considered in the mix-design process, as it normally is for AC meeting EN standards (Dondi et al. 2014a, 2014b, Simone et al. 2012).

Along with mix-design a range of refinement processes should be started in order to assess the durability of the asphalt mixtures, the bitumen-aggregates affinity and the need of additives such as fibers, adhesion promoters and similar (Sangiorgi et al. 2014, 2016, Mazzotta et al. 2015). Studies should consider the use of innovative Warm Mix binders as well as of cold mix asphalts and flux binders for patch asphalt in bags (Vignali et al. 2014, Dondi et al. 2014c).

Table 3. Estimate of tailings consumption for the production of 3 layered bituminous pavement.

\begin{tabular}{|c|c|c|c|c|c|c|}
\hline No. & $\begin{array}{l}\text { Bituminous } \\
\text { Layer }\end{array}$ & $\begin{array}{c}\text { Assumed } \\
\text { Thickness } \\
(\mathrm{cm})\end{array}$ & $\begin{array}{l}\text { Assumed } \\
\text { Binder } \\
\text { Percentage }\end{array}$ & $\begin{array}{l}\text { Mixture } \\
\text { Bulk Density } \\
\left(\mathrm{kg} / \mathrm{m}^{3}\right)\end{array}$ & $\begin{array}{l}\text { Layer Weight } \\
\text { per } 1 \mathrm{~m}^{2} \\
(\mathrm{~kg})\end{array}$ & $\begin{array}{l}\text { Material Weight } \\
\text { per } 1 \mathrm{~m}^{2} \\
(\mathrm{~kg})\end{array}$ \\
\hline 1 & Surface Layer & 4 & $5.5 \sim 6 \%$ & 2350 & 94 & 88.6 \\
\hline 2 & Binder Layer & 6 & $5 \sim 5.5 \%$ & 2300 & 138 & 130.8 \\
\hline 3 & Base Layer & 10 & $4 \sim 4.5 \%$ & 2250 & 225 & 215.4 \\
\hline
\end{tabular}

\subsection{Use of Panasqueira tailings for alkali-activated artificial aggregates}

Previous studies on the production of artificial aggregates through alkali-activation of Panasqueira mining waste mud (Figure 3 left), have shown the wide range of potential lines of development for the reuse of mud tailings. The variety of alkali-activated admixtures where the 
variables are mainly the kind of precursors and activators, as well as their proportions and curing conditions, make the field of research and applications vast.

In the area of road construction aggregates, from medium to coarse size, are essential for the production of workable loose materials that, when compacted, form the bearing skeleton of pavement layers and foundations. Nevertheless, added value should be given to the artificial aggregates to overcome the production and marketing costs, especially when used in rich layers such as the bituminous ones.

On-going studies within REMINE project are developing strong (low Los Angeles) and durable (high freeze and thaw resistance) aggregates with polyhedric shape that optimize packing and reduces stress concentrations under traffic loading on the bituminous layers. Aggregates shape and size, as well as mixture grading and packing are the most important variables of the study (Figure 3 centre).
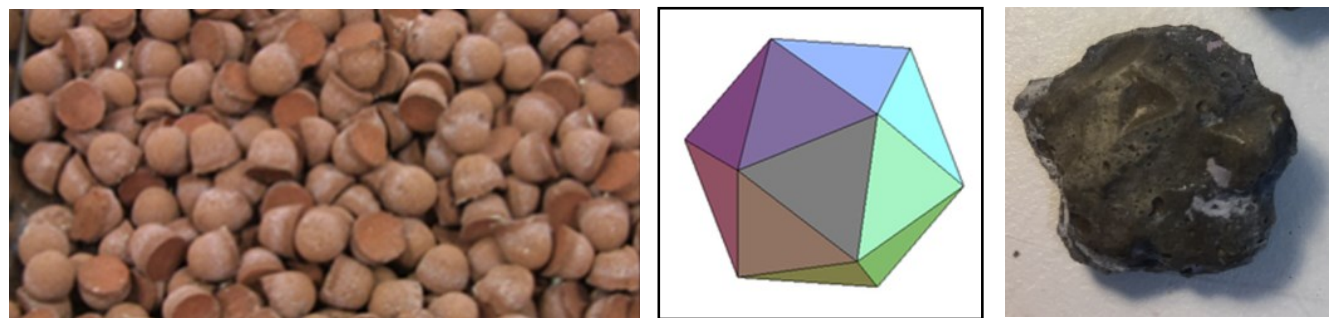

Figure 3. Artificial aggregates: preliminary studies, engineered shape and surfaces

In parallel, surface textured artificial aggregates are being developed for high friction pavement surfacings (Figure 3 right). Starting from the well-known effects of micro-roughness of traffic-exposed aggregates on the skid resistance properties (safety) of bituminous pavements, a set of highly textured alkali-activated aggregates is now under assessment.

Binder adhesion (affinity) and polishing (PSV) aggregates characteristics are taken into account in this promising work also adopting new testing procedures (Lamperti et al., 2015a, 2015b).

\subsection{Use of Panasqueira tailings for alkali-activated pre-cast segments production}

In addition to the use of tailings for the production of bituminous materials and engineered artificial aggregates, a valid option is to develop alkali-activated bound pre-cast elements for road functional furniture. The large number of type and sizes of segments opens a wide perspective to the recycling of Panasqueira mud and coarse waste materials and significantly increases the potential range of marketed high quality and high value products. Among these, culverts, gutters, curbs and, especially, safety barriers are the most diffuse ones (Figure 4).
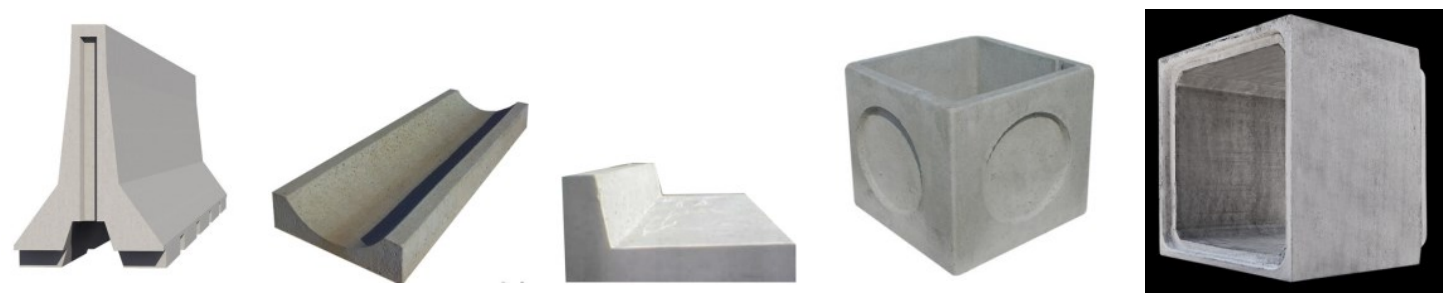

Figure 4. Most diffuse pre-cast segments for road construction purposes.

Table 4 shows a rough estimate of the volume quantities of alkali-activated and coarse aggregates admixtures needed for the production of some different pre-cast segments. Their production in Panasqueira site could make use of the traditional pre-casting processes of concrete elements, taking into account that alkali-activated production and curing are different.

Product properties should undergo standard testing procedures for certification and CE marking, this is particularly relevant for road safety rigid barriers that could be moulded (after commercial agreements) according to existing and certified products. Constituent material changes, 
in fact, will only require computer aided virtual crash testing of the barrier, avoiding major costs of real scale crash testing.

It is evident that larger pre-cast segments such as barriers and box culverts will use larger volumes of alkali-activated tailings from Panasqueira piles and lagoons.

Table 4. Estimate of material volumes for the production of single pre-cast segments.

\begin{tabular}{|c|c|c|c|c|c|c|}
\hline No. & $\begin{array}{l}\text { Pre-cast } \\
\text { segment }\end{array}$ & $\begin{array}{l}\text { Dimensions } \\
\text { (m) }\end{array}$ & $\begin{array}{l}\text { Assumed } \\
\text { length } \\
\text { (L) } \\
\end{array}$ & $\begin{array}{l}\text { Surface Area } \\
\left(\mathrm{m}^{2}\right)\end{array}$ & $\begin{array}{l}\text { Volume } \\
\left(\mathrm{m}^{3}\right)\end{array}$ & $\begin{array}{l}\text { Scheme } \\
\text { (not to scale) }\end{array}$ \\
\hline 1 & Box culvert & $2 \times 2$ & 1.5 & 2.28 & 3.42 & \\
\hline 2 & Box culvert & $1 \times 1$ & 1.5 & 1.01 & 1.52 & \\
\hline 3 & $\begin{array}{l}\text { New Jersey } \\
\text { barrier }\end{array}$ & 1.1 (height) & $3 / 6$ & 0.44 & $1.32 / 2.64$ & \\
\hline 4 & V channel & 0.6 (height) & 1 & 0.10 & 0.10 & \\
\hline 5 & Gutter & - & 0.5 & 0.13 & 0.06 & \\
\hline 6 & Curb & 0.25 (height) & 0.5 & 0.04 & 0.02 & \\
\hline
\end{tabular}

\section{CONCLUSIONS}

The mine of Panasqueira in the Beira Interior region has been active for over 125 years. Tungsten is the main extracted ore and the mining activity future depends on its world commercial value. The mine also produces huge amounts of waste tailings every day that are piled in dams and pumped in mud lagoons. These waste materials could be seen as the source of employment for the local people in case the mining activity is stopped or reduced. Conversion to the production of construction materials is a viable alternative also for the recycling of the million of tons of waste rocks.

The use of coarse tailings for road construction has been proven feasible provided that the installation of a stable asphalt concrete plant and aggregates crushing and sieving is implemented in the mine areas. Cold, warm and hot bituminous mixtures could be designed, produced and transported within a profitable market range in the districts of Covilha, Fundao, Belmonte, Castelo Branco and Coimbra. 
A rough calculation estimates that more than 3,000 tons of tailings could be used for the construction of just $1 \mathrm{~km}$ of two lane rural road, only in the asphalt concrete layers. This could rise to more than double if tailings are used also for foundation layers.

Another form of cost-effective recycling makes use of mud tailings for the production of alkali-activated binders and mortars. Tailings have been proven to be excellent precursors in the alkali-activation processes that could be a viable alternative to the use of OPC that, on the contrary, is not fully compatible with the Panasqueira schists and shales.

The fabrication of artificial aggregates by alkali-activation was attempted and gave positive results suggesting that part of the muds can be recycled into engineered particles having special features such as water treatment capabilities, enhanced strength and shape as well as highly textured surfaces for improved skid-resistance bituminous pavements. Larger artificial aggregates could be seen as paving blocks for low traffic pavements and footpath surfaces.

Finally, large volumes of waste rock tailings could be recycled in the industrial production of pre-cast segments for civil engineering construction purposes, in particular for transportation infrastructures. Alkali-activation of fines from mud and other precursors could form the binding paste for concrete-like elements such as box-culverts, gutters, channels, curbs and especially safety barriers, containing also coarse tailing aggregates. The correct design of these admixtures could lead to the production of segments with enhanced characteristics if compared to the cement concrete ones.

All these aspects are being studied within the on-going REMINE research program (H2020 RISE-Marie Curie Action) that aims to the reuse of mining waste into innovative geopolymericbased structural panels, precast, ready mixes and in-situ applications.

\section{REFERENCES}

Antunes, C.S.R., 2009. Development of polymeric-based revetment tiles reusing Panasqueira waste-rock coarse particles, Master dissertation, University of Beira Interior, Covilhã, July (only available in Portuguese).

Ávila, P. F., Silva, E. F., Salgueiro, A. R. \& Farinha, J. A. 2008. Geochemistry and mineralogy of mill tailings impoundments from the Panasqueira mine (Portugal): implications for the surrounding environment. Mine Water and the Environment 27 (4), 210-224.

Bakharev, T., Sanjayan J.G., Cheng Y.B. 1999. Effect of elevated temperature curing on properties of alkali-activated slag concrete. Cem Concr Res. 29: 1619-25.

Castro-Gomes, J. P., Silva, A. P., Cano, R. P., Durán Suarez, J. \& Albuquerque, A. 2012. Potential for reuse of tungsten mining waste-rock in technical-artistic value added products. Journal of Cleaner Production, 25, 34-41.

Cavey, G. \& Gunning, D., 2006. Updated Technical Report on the Panasqueira mine, Distrito de Castelo Branco, Portugal, ORE-QUEST, p. 67.

Dinis de Almeida, M., Castro Gomes, J.P. \& Pereira de Oliveira, L.A.. 2006. Valorização de resíduos de minas em pavimentos de baixo custo, Revista Valorização de Resíduos, Ano 3, Número 9, Centro de Valorização de Resíduos.

Dinis-Almeida, M., Castro-Gomes, J., Sangiorgi, C., Zoorob, S.E., Afonso, M.L. 2016. "Performance of Warm Mix Recycled Asphalt containing up to 100\% RAP". Construction and Building Materials, 112:1-6.

Dondi G., Sangiorgi C., Lantieri C., Simone A., Vignali V. \& Lamperti R. 2014a. Performance evaluation of Construction and Demolition and other waste materials. 3rd International Conference on Transportation Infrastructures - ICTI 2014, Pisa, April 22-25. Tay\&Fran Group, ISBN 978-1-138-00147-3.

Dondi, G., Mazzotta, F., Sangiorgi, C., Pettinari, M., Simone, A., Vignali, V. \& Tataranni, P. 2014b. Influence of cement and limestone filler on the rheological properties of mastic in cold bituminous recycled mixtures. Sustainability, Eco-efficiency and Conservation in Transportation Infrastructure Asset Management - Losa \& Papag. (Eds), pp.61-67, Tay\&Fran Group. ISBN 978-1-138-00147-3.

Dondi, G., Tataranni, P., Pettinari, M., Sangiorgi, C., Simone, A. and Vignali, V. 2014c. Crumb Rubber in Cold Recycled Bituminous Mixes: comparison between Traditional Crumb Rubber and Cryogenic Crumb Rubber. Construction and Building Materials, Volume 68, 15 October 2014, Pages 370-375.

Feret, R. 1939. Revue des Materiaux de Construction et Travaux Publics; 352:1.

Franco, A., Vieira, R. \& Bunting, R. 2014. The Panasqueira Mine at a Glance. Tungsten, 3(June), 1-12. 
Garcia, JIE., Fluentes, AF., Gorokhovsky, A., Fraire-Luna, PE. \& Mendoza-Suarez, G. 2003. Hydration products and reactivity of blast-furnace slag activated by various alkalis. J Am Ceram Soc. 86 (12):2148-53.

García-Lodeiro, I., Palomo, A., Fernández-Jimenez, A. \& Macphee, DE. 2001. Compatibility studies between $\mathrm{N}-\mathrm{A}-\mathrm{S}-\mathrm{H}$ and $\mathrm{C}-\mathrm{A}-\mathrm{S}-\mathrm{H}$ gels. Study in the ternary diagram Na2O-CaO-A12O3-SiO2-H2O. Cem Concr Res. 41:923-31.

Godinho, B., Abreu, M.M. \& Magalhaes, M.C., 2010. Avaliação biogeoquímica dos solos e do medronheiro na área mineira da Panasqueira. Revista de Ciências Agrárias 33 (1), 226-235. ISSN 0871-018X (only available in Portuguese).

Juenger, MCG, Winnefeld, F, Provis, JL, Ideker, JH. 2011. Advances in alternative cementitious binders. Cem Concr Res. 41:1232-43.

Krivenko, P. 2002. Alkaline cements: from research to application. In: Geopolymers 2002 - turn potential into profit, Melbourne. Proceedings. Hotel Sofitel, Melbourne, Australia; p. 28-29.

Lamperti, R., Grenfell, J., Sangiorgi, C., Lantieri, C. \& Airey G. 2015a. Influence of waxes on adhesion properties of bituminous binders. Construction and Building Materials. Elsevier. Volume 76, $1 \mathrm{Fe}-$ bruary 2015, Pages 404-412.

Lamperti, R., Lantieri, C., Sangiorgi, C., Bitelli, G. \& Simone, A. 2015b. Semi-automatic evaluation of the degree of bitumen coverage on bitumen-coated aggregates. RILEM Bookseries Volume 11, 26 September 2015, Pages 15-24.

Malolepszy, J. 1993. Proceedings of $3^{\text {rd }}$ international symposium on cement and concrete. Beijing, China.

Mazzotta, F., Sangiorgi, C., Vignali, V., Lantieri, C., Dondi, G. 2015. Rheological characterization of bituminous mastics containing waste bleaching clays. RILEM Bookseries, Volume 11, 26 September 2016, Pages 595-606. ISSN: 22110844.

Pacheco-Torgal, F., Castro-Gomes, J.P. \& Jalali, S. 2009. Utilization of mining wastes to produce geopolymer binders, in: J.L. Provis, J.S.J. van Deventer (Eds.), Geopolymers - Struct. Process. Prop. Ind. Appl., Woodhead Publishing Limited, 2009: pp. 267-293.

Palomo, A., Grutzeck, M.W. \& Blanco, M.T. 1999. Alkali-acivated Fly Ashes. A Cement for Future. $\mathrm{Ce}$ ment and Concrete Research. n. 29, pp. 1323-1329.

Pereira, C.N.G., Oliveira, L.P. \& Castro-Gomes, J.P., 2009. Influence of natural coarse aggregates size, mineralogy and water content on the permeability of structural concrete. Construction and Building Materials 23 (2), 602-608.

Purdon, AO. 1940. The action of alkalis on blast-furnace slag. J Soc Chem Indust. 59:191-202.

Sangiorgi, C., Tataranni, P., Simone, A., Vignali, V., Lantieri, C. \& Dondi, G. 2014. Waste bleaching clays as fillers in hot bituminous mixture. Construction and Building Materials, 73, 320-325.

Sangiorgi, C., Tataranni, P., Simone, A., Vignali, V., Lantieri, C. \& Dondi, G. 2016. Assessment of waste bleaching clay as alternative filler for the production of porous asphalts. Construction and Building Materials, 109, 1-7.

Silva, I., Castro-Gomes, J.P., \& Albuquerque, A., 2012. Mineral Waste Geopolymeric Artificial Aggregates as Alternative Materials for Wastewater-Treatment Processes: Study of Structural Stability and pH Variation in Water, J. Mater. Civ. Eng. 1-6.

Simone, A., Vignali, V., Lantieri, C. 2012. A new "frugal" approach to road maintenance: 100\% Recycling of a deteriorated flexible pavement. 7th International Conference on Maintenance and Rehabilitation of Pavements and Technological Control, MAIREPAV 2012. New Zealand; 28 August 2012 through 30 August 2012; Code 110271.

Smith, M. 2006. Panasqueira the tungsten giant at 100+. Operation focus. International Mining, 10-14.

Van Jaarsveld, JGS, Van Deventer, JSJ \& Lorenzen L. 1997. The potential use of geopolymeric materials to immobilize toxic metals: part I. Theory and applications. Minerals Eng. 10(7):659-69.

Vargas, A. S., Dal Molin, D. C. C., Masuero, Â. B., Vilela, A. C. F., Castro-Gomes, J., \& de Gutierrez, R. M. 2014. Strength development of alkali-activated fly ash produced with combined $\mathrm{NaOH}$ and $\mathrm{Ca}(\mathrm{OH}) 2$ activators. Cement and Concrete Composites. 53, 341-349.

Vignali, V., Mazzotta, F., Sangiorgi, C., Simone, A., Lantieri, C., Dondi, G. 2014. Rheological and 3D DEM Characterization of Potential Rutting of Cold Bituminous Mastics. Construction and Building Materials. Volume 73, 2014, Pages 339-349. 